\title{
Quantitative Electron Probe Microanalysis in the System Fe-Sn-C Using the Claisse-Quintin Relation
}

\author{
W. Fredriksz, * H. Koster and B. H. Kolster \\ Twente University of Technology, Department of Mechanical Engineering, Materials Science Section, P.O. Box 217, \\ 7500 AE Enschede, The Netherlands
}

\begin{abstract}
Quantitative interpretation of EPMA measurements was required for the construction of the Fe-Sn-C phase diagram. This involved the conversion of measured $x$-ray intensities into concentrations, which is difficult for a light element (such as $\mathrm{C}$ ) being present among heavier elements (Fe and $\mathrm{Sn}$ ). To meet this problem, firstly the various intensity-concentration conversion methods from the literature have been studied and are briefly surveyed. The Claisse-Quintin relation with constant influence coefficients was selected as the algorithm for multiple regression purposes, which was applied to reference standard data. Calibration functions are obtained for $\mathrm{Sn}$ and $\mathrm{C}$, which are used in a simple iteration procedure. This procedure has been used for the conversion of $\mathrm{Sn}$ and $\mathrm{C} x$-ray intensities into concentrations. The method shows a relative accuracy of about $\mathbf{5 \%}$.
\end{abstract}

\section{INTRODUCTION}

In view of a study concerning the diffusion in the ternary system $\mathrm{Fe}-\mathrm{Sn}-\mathrm{C},{ }^{1}$ the Fe-rich part of the phase diagram had to be determined. In particular, some isothermal sections of the phase diagram were determined. To that end, electron probe microanalysis (EPMA) was performed on a number of equilibrated single- and multi-phase $\mathrm{Fe}-\mathrm{Sn}-\mathrm{C}$ alloys, implying the accurate determination of the concentrations from the $\mathrm{x}$-ray intensities.

The conversion of intensities into concentrations has been the subject of many studies in the past two decades, originally concerning $x$-ray fluorescence analysis (XRFA). Most frequently treated are heavyelement alloys and their corrections for mutual interference effects. The procedure for light elements, however, is less well established, because the quantitative $\mathrm{x}$-ray analysis of the long-wavelength $\mathrm{K} \alpha$ lines is difficult. Unfortunately, the mass absorption coefficients for long-wavelength $x$-rays are not well known. Additional effects influencing light element analysis include overlapping $\mathrm{x}$-ray peaks, chemical bonding shifts and surface contamination. ${ }^{2}$

Hence it is clear that quantitative microanalysis in the system $\mathrm{Fe}-\mathrm{Sn}-\mathrm{C}$, in particular the analysis of $\mathrm{C}$ in the presence of $\mathrm{Fe}$ and $\mathrm{Sn}$, is not a simple task. This paper describes a semi-empirical method for the determination of concentrations, for which the ClaisseQuintin relation has been selected as the algorithm in a simple correction procedure to be applied.

\section{VARIOUS CORRECTION PROCEDURES}

A survey of mathematical correction procedures has been given by Jenkins. ${ }^{3}$ Most of the mathematical

* Present address: Nederlandse Philips Bedrijven B.V., HIG ELCOMA/HOC, gebouw BL, P.O. Box 218, 5600 MD Eindhoven, The Netherlands. correction procedures used in $\mathrm{x}$-ray spectrometry fall into three main categories, namely the fundamental parameter approach (in practice known as the ' $\mathrm{ZAF}$ ' correction method), the concentration correction method and the intensity correction method. It should be noted that the ZAF correction mainly is applied in EPMA (MAGIC $\mathrm{IV}^{4}$ ), whereas the concentration correction and the intensity correction method are used in XRFA. ${ }^{5}$

As the usual ZAF correction is based on measurements performed within the electron energy range from 20 to $30 \mathrm{keV}$, the procedure becomes increasingly inaccurate for lighter elements. Although the method of Brown and Parobek ${ }^{6,7}$ should be suitable for light element analysis, as it has been applied for the electron energy range from 6 to $15 \mathrm{keV}$, a relative accuracy of only $15-20 \%$ could be obtained up till now. ${ }^{8}$ This is mainly due to a lack of accurate input parameters (e.g. mass absorption coefficients) and approximations in the corrections. Hence in our case Fe and Sn could have been quantified by the usual ZAF correction method, but determination of the $\mathrm{C}$ concentration would give inaccurate results (also in the case of determination by difference).

An alternative approach is to apply an XRFA correction method to EPMA measurements, which can be justified by the fact that both in XRFA and in EPMA the $\mathrm{x}$-ray quanta to be measured are generated by previous energy absorption in the sample. The main difference is the appearance of the energy in the primary stage, being polychromatic in XRFA and monochromatic in EPMA. However, this difference is supposed not to affect the physics of generation of the characteristic $\mathrm{x}$-rays.

In our case, the concentration correction method with the so-called alpha coefficients is to be preferred. However, because of the lack of accurate fundamental parameters the calculation of the alpha coefficients ${ }^{5}$ from first principles cannot be performed. Instead, they have to be determined by regression analysis of 
data obtained from a relatively large number of calibration standards. To that end a variety of regression algorithms can be used, from which the most relevant one for our system has been selected.

\section{SELECTION OF THE CORRECTION ALGORITHM}

In the past, various intensity-concentration relationships have been discussed. A first modification of the linear model (where the weight fraction of an element to be analysed in an alloy is equated to its relative $\mathrm{x}$-ray intensity) was proposed by Lachance and Traill, ${ }^{9}$ giving account to the influence of interfering elements. It can be shown that for a binary system this XRFA model is described by the equation of a hyperbole. An analogous hyperbolic model has been described by Ziebold and Ogilvie ${ }^{10}$ in their empirical method for EPMA. Hence this is an example of EPMA measurements obeying a hyperbolic intensity-concentration relationship stemming from XRFA.

Later, Rasberry and Heinrich ${ }^{11,12}$ suggested additional terms in the Lachance-Traill equation, in order to account for fluorescence. Further, a more accurate fit for experimental results may be expected ${ }^{12}$ from expressions with even more terms, as proposed, for instance, by Claisse and Quintin: ${ }^{13}$

$$
\frac{W_{i}}{I_{i}}=1+\sum_{j \neq i} \alpha_{i j} W_{j}+\sum_{i \neq i} \alpha_{i j j} W_{j}^{2}+\sum_{j, k \neq i} \alpha_{i j k} W_{j} W_{k}
$$

where

$W_{i}$ is the weight fraction of element $i$ in the alloy; $I_{i}$ is the ratio of the intensity of $i$ in the alloy and the intensity of $i$ obtained from pure $i$;

$j$ and $k$ are interfering elements;

$\alpha_{i j}$ is the coefficient expressing the first-order influence of $j$ on the intensity of $i$;

$\alpha_{i j j}$ is the coefficient expressing the second-order influence of $j$ on the intensity of $i$;

$\alpha_{i j k}$ is the coefficient expressing the cross-effect of $j$ and $k$ on the intensity of $i$.

This equation has been tested by Rousseau and Claisse $^{14}$ for various multi-component systems with good results. However, Tertian ${ }^{15}$ criticized the Claisse-Quintin relation by stating that the $\alpha$ coefficients have to be taken at the proper $W_{i}$ level. He therefore introduced concentration-dependent $\alpha$ coefficients into the Lachance-Traill equation. Further, for systems with more than two components, he suggested a second-order correction factor for fluorescence cross-effects.

In order to meet the shortcomings as mentioned by Tertian, ${ }^{15}$ Lachance and Claisse ${ }^{16}$ recently proposed an algorithm with a validity over the entire concentration range, in which the $\alpha$ coefficients have to be determined at the concentration of the matrix, $W_{\mathrm{m}}$.

From the correction algorithms considered, the one with concentration-dependent influence coefficients is to be preferred. However, for reasons of simplicity in the computation, that is regression, we chose the Claisse-Quintin relation with constant $\alpha$ coefficients. This restriction is justified by the fact that we are only interested in the Fe-rich part of $\mathrm{Fe}-\mathrm{Sn}-\mathrm{C}$ phase diagram, that is about $0-25$ at. $-\%$ Sn $(0-42$ wt.- $\%)$ and $0-30$ at. $-\%$ C $(0-7$ wt $-\%)$. So, for the calibration of EPMA measurements with reference standard alloys, we chose the following expression for a ternary system A-B-C:

$$
\frac{W_{\mathrm{A}}}{I_{\mathrm{A}}^{\prime}}=1+\sum_{i=\mathrm{B}, \mathrm{C}} \alpha_{i \mathrm{~A}}^{\prime} W_{i}+\sum_{i=\mathrm{B}, \mathrm{C}} \alpha_{i i \mathrm{~A}}^{\prime} W_{i}^{2}+\alpha_{\mathrm{BCA}}^{\prime} W_{\mathrm{B}} W_{\mathrm{C}}
$$

It should be recalled that $I_{\mathrm{A}}{ }^{\prime}$ is the normalized intensity of element $A$ in the alloy with respect to pure A:

$$
I_{\mathrm{A}}^{\prime}=\frac{I_{\mathrm{A}, \text { alloy }}}{I_{\mathrm{A}, \text { pure metal }}}
$$

For low concentrations of $\mathrm{A}$ (in our case $\mathrm{Sn}$ and $\mathrm{C}$ ), a more accurate result may be obtained if, instead of normalizing with respect to pure $A$, the intensity $I_{\mathrm{A} \text {, alloy }}$ is referred to the one of a reference standard with a low concentration of $\mathrm{A}$, to be chosen as the main standard. Thus:

$$
I_{\mathrm{A}}=\frac{I_{\mathrm{A}, \text { alloy }}}{I_{\mathrm{A}, \text { main standard }}}
$$

For this case the Claisse-Quintin relation changes to:

$$
\frac{W_{\mathrm{A}}}{I_{\mathrm{A}}}=\alpha_{0 \mathrm{~A}}+\sum_{i=\mathrm{B}, \mathrm{C}} \alpha_{\mathrm{iA}} W_{i}+\sum_{i=\mathrm{B}, \mathrm{C}} \alpha_{i \mathrm{~A}} W_{i}^{2}+\alpha_{\mathrm{BCA}} W_{\mathrm{B}} W_{\mathrm{C}}
$$

where the regression coefficients differ from the ones mentioned before (and therefore are indicated here without a prime), involving additionally $\alpha_{0 \mathrm{~A}}$.

\section{EXPERIMENTAL}

\section{Preparation of standard alloys}

The reference standard alloys were prepared from 99.99\% pure $\mathrm{Fe}, 99.935 \%$ pure $\mathrm{Sn}$ and $99.9994 \%$ pure graphite by melting in a high-frequency induction furnace under pure argon (research grade), after evacuation down to $1.3 \mathrm{mPa}$. In order to achieve a homogeneous melt, the liquid state was maintained for $10 \mathrm{~min}$. After furnace cooling the ingot was turned upside down, and the procedure repeated.

Subsequently, a heat treatment a few hundred degrees below the melting temperature for $1 \mathrm{~h}$ was carried out, in order to eliminate the as-cast structure.

Finally, the ingots were sealed in evacuated quartz tubes $(1.3 \mathrm{mPa})$ for equilibration in a resistance furnace. To that end one of the following heat treatments was applied: $600 \mathrm{~h}$ at $1073 \mathrm{~K}, 200 \mathrm{~h}$ at $1198 \mathrm{~K}$ or $80 \mathrm{~h}$ at $1323 \mathrm{~K}$. These temperatures were selected in view of the isothermal sections of the phase diagram to be determined. In order to retain the high-temperature structure the quartz tube was broken and the ingot water quenched.

By means of a grinding wheel two pieces were slit from the central part of each ingot. One piece was used for chemical analysis, while the other was mounted in Struers $\mathrm{Fe}$-containing mounting resin to be used as the actual standard in the microprobe. To 
this end the usual grinding and polishing procedures were followed, finally polishing with a mixture of $0.05 \mu \mathrm{m}$ Ce oxide and $\mathrm{Cr}$ oxide particles (LECO).

Chemical analysis was performed on the part of the alloy adjacent to the mounted piece, in order to minimize the influence of an eventual segregation in the ingot. The part was hammered to small pieces and divided into two portions, one for $\mathrm{C}$ analysis and the other for $\mathrm{Sn}$ and $\mathrm{Fe}$ analysis.

$\mathrm{C}$ analysis was performed with semi-automatic infrared absorption analytical equipment (LECO CS241), which was calibrated before and after each measurement. By this method a relative accuracy of about $1.5 \%$ could be obtained.

The $\mathrm{Sn}$ and $\mathrm{Fe}$ concentrations were determined by means of wet chemical analysis, involving dissolution of the alloy and subsequent titration. ${ }^{17,18}$ The relative accuracy of this method was estimated to be $0.5 \%$.

The experimental procedure described so far was followed for the single-phase standard alloys, so that the chemical analysis data could be simply related to the intensity measurements of these alloys. However, for the two-phase alloys, which contained Fe-Sn carbides, a different procedure had to be followed. As we have determined experimentally, $\mathrm{Fe}-\mathrm{Sn}$ carbides cannot be obtained as a single phase, either by melting or by sintering. The only way left is to isolate these carbides from the two-phase alloys prior to chemical analysis, in order to be used as standard alloys in the microprobe.

Isolating carbides out of the two-phase alloys involves electrochemical dissolution of the metallic phase. To that end the two-phase alloy was inserted as the anode of a water-cooled galvanic cell in a $6 \%$ solution of perchloric acid in methanol. Every $2 \mathrm{~min}$ the alloy was subjected to ultrasonic vibration in methanol, in order to loosen the carbide particles. Finally, the particles were cleaned by flushing with fresh methanol and dried.

$\mathrm{X}$-ray diffraction showed that an amount of the metallic phase was still present. Therefore, subsequent preferential dissolution of this metallic phase in $2.5 \%$ $\mathrm{HCl}$ solution was necessary, the result being checked by $\mathrm{x}$-ray diffraction. This procedure was also followed for $\mathrm{Fe}_{3} \mathrm{Sn}$ out of the two-phase alloy. The particles so obtained were subjected to wet chemical analysis as described before. However, some impurity effects had to be considered for the carbides, because the cumulative concentration for $\mathrm{Fe}, \mathrm{Sn}$ and $\mathrm{C}$ reached only $84 \%$. Weight analysis performed after annealing in a reducing atmosphere $\left(\mathrm{Ar}-5 \% \mathrm{H}_{2}\right)$ showed a weight loss of about $16 \%$, whereas thermogravimetric analysis in an inert atmosphere $\left(\mathrm{N}_{2}\right)$ resulted in a weight loss of only about $6 \%$. Hence it can be concluded that about $6 \%$ is moisture adhered to the surface of the small powder particles $(\mathrm{Ca} 10 \mu \mathrm{m})$, and the remaining $10 \%$ represents oxygen. For these impurity effects the wet chemical analysis data of the carbides had to be corrected by $16 \%$ before use as standard reference data in the microprobe (see Results and Discussion).

Apart from the single-phase alloys and the twophase alloys containing $\mathrm{Fe}_{3} \mathrm{Sn}$ and carbides, some homogenized plain carbon steels, supplied by the Metaalinstituut TNO/Apeldoorn, were also used as
Fe-C standards. These alloys were mounted and polished, their composition being determined (wet) chemically on Fe and $\mathrm{Sn}$ as well as $\mathrm{C}$, in the same way as described earlier for the single-phase alloys.

\section{EPMA}

Electron probe microanalysis was performed with a computerized ARL-SEMQ. Before the actual measurements were carried out a vacuum of $0.65 \mathrm{mPa}$ was produced by means of a turbomolecular pumping unit (Leybold Heraeus 450); this pressure increased to $1.3 \mathrm{mPa}$ as soon as the decontamination oxygen gas jet was activated. Subsequently, the high-tension unit was stabilized at $10 \mathrm{kV}$ and a sample current of $200 \mathrm{nA}$ (objective aperture of $200 \mu \mathrm{m}$ size).

The intensity measurements for each of the elements $\mathrm{Fe}, \mathrm{Sn}$ and $\mathrm{C}$ consisted of one measurement for peak intensity and two for background intensities, one on each side of the peak. The two background values were averaged at the peak position and this value was used to compute the net peak intensity corrected for drift and dead time.

The $C$ intensity measurement $\left(\lambda_{\mathrm{CK} \alpha}=4.470 \mathrm{~nm}\right)$ involved a $\mathrm{PbSD}$ analyser in combination with a flowproportional detector $\left(\mathrm{Ar}-10 \% \mathrm{CH}_{4}\right)$, and for the $\mathrm{Fe}$ intensity measurement $\left(\lambda_{\mathrm{FeK} \alpha_{1.2}}=0.194 \mathrm{~nm}\right)$ and for the $\mathrm{Sn}$ intensity measurement $\left(\lambda_{\mathrm{Sn} \boldsymbol{\alpha}_{1}}=0.360 \mathrm{~nm}\right)$ an $\mathrm{LiF}$ analyser was used in combination with a xenon detector.

In view of additional measurements on diffusion couples, the calibration for $\mathrm{Fe}, \mathrm{Sn}$ and $\mathrm{C}$ of each standard was performed simultaneously, that is at $10 \mathrm{kV}$.

\section{RESULTS AND DISCUSSION}

As mentioned in the previous section, the chemical analysis data for the carbides had to be corrected for impurity effects before use as standard reference data. One of these effects to be corrected for is moisture adhering to the surface of the small powder particles. As this is supposed to be a mixing, i.e. a diluting, effect, its correction is simple. Correction for the occurrence of oxides, however, needs further consideration.

Firstly, it must be recalled that the melting process under pure argon was preceded by evacuation to high vacuum $(1.3 \mathrm{mPa})$. This makes the presence of $10 \mathrm{wt}-$ $\%$ of oxygen in the melt improbable, which leaves the electrochemical action of perchloric acid as the only possibility for uptake of oxygen.

Secondly, with two different methods of analysis, i.e. (wet) chemical analysis and weight analysis in a reducing and inert atmosphere, complementary results could be obtained for the composition distribution: $\mathrm{Fe}+\mathrm{Sn}+\mathrm{C} 84 \mathrm{wt}-\%$, oxygen $10 \mathrm{wt}-\%$ and moisture $6 \mathrm{wt}-\%$. In other words, the $\mathrm{Fe}, \mathrm{Sn}$ and $\mathrm{C}$ present in the carbides before the electrochemical process has been conserved in $84 \mathrm{wt}-\%$ of the particles obtained after extraction, and $10 \mathrm{wt}-\%$ has resulted from uptake of oxygen. Therefore for the correction of the 
presence of oxygen, we think that it is unimportant in what oxide the oxygen is present. In this sense it can be treated as a diluting element, as in the case for the moisture. Hence the correction for the two impurity effects can be taken together to be $16 \mathrm{wt}-\%$.

Before the actual calibration procedure is described, the $\mathrm{C}$ intensity measurements need detailed consideration. In our measurements the $C$ peak shift detected with varying matrix (graphite or carbide) was negligible, owing to the large slit size of the detector in order to obtain a sufficient large signal. This is in contrast to the results of Bishop. ${ }^{19}$ Further, no contamination of the specimen's surface by the build-up of $C$ was observed under the given conditions. However, the net $\mathrm{C}$ intensity on $\mathrm{Fe}_{3} \mathrm{Sn}$ (no C) and on pure $\mathrm{Fe}$ and pure $\mathrm{Sn}$ revealed a residual value, which was found to increase with higher Sn content. A similar effect has been observed on pure Fe by Fisher and Farningham ${ }^{20}$ and Bishop. ${ }^{19}$ The former authors ascribed this effect to a very thin $C$ film present on the standard, owing to the breakdown of hydrocarbons, which is just balanced by the removal of $\mathrm{C}$ by the oxygen jet. The latter author also took into account the possibility of initial contamination left on the sample after polishing. As we still observed the effect on freshly polished pure Fe and pure Sn standards without the slightest detectable contamination, we think, that it may be attributed to scattered x-radiation connected to backscattered electrons (e.g. from Aquadag paint inside the apparatus). Therefore, the $\mathrm{C}$ intensity was additionally corrected for this effect, involving the weighted average from the value on pure $\mathrm{Fe}$ and on pure $\mathrm{Sn}$.

$\mathrm{Sn}$ and $\mathrm{C}$ were the elements for which the calibration and, later, the conversion of intensities into concentrations were carried out, Fe being determined by difference. The reason for this is found in counting statistics, giving a large standared deviation in the concentration of the main element, Fe. If, for example, the calibration were to be performed with $\mathrm{Sn}$ and $\mathrm{Fe}, \mathrm{C}$ then being determined by difference, the standard deviation in $\mathrm{Fe}$ concentration would result in a relative large inaccuracy in the $\mathrm{C}$ concentration.

In order to account for effects of long-term drift, the measurements on the series of standard specimens were repeated eight times. Alternately, the unknown alloys were measured. In order to minimize the influence of short-term drift, two alloys out of the middle of the standard specimen series, with a relatively high intensity, were chosen as main standards for $\mathrm{Sn}$ and $\mathrm{C}$, respectively: $\mathrm{Fe}-6.77$ at.-\% $\mathrm{Sn}-0.50$ at.$\% \mathrm{C}$ and $\mathrm{Fe}-0.26$ at. $-\% \mathrm{Sn}-3.99$ at. $-\% \mathrm{C}$. It should be noticed, that, in view of the aimed construction of the phase diagram, the concentration is expressed as atomic percentage, whereas for the Claisse-Quintin relation concentrations as weight fractions are required. Now, within each standard series of measurements the Sn intensity of the standards was normalized with that of the former alloy, and the $\mathrm{C}$ intensity with that of the latter alloy. Hence, from all eight series of measurements eight normalized $\mathrm{Sn}$ intensities and eight normalized $\mathrm{C}$ intensities were obtained for each standard. These values were averaged, giving finally a mean normalized $\mathrm{Sn}$ intensity and a $\mathrm{C}$ intensity per standard.
These $\mathrm{Sn}$ and $\mathrm{C}$ intensity ratios together with the compositions of the standard alloys were used for multiple regression with the Claisse-Quintin relation using a DEC-10 computer. From the calculations two sets of regression coefficients (i.e. influence coefficients) were obtained, one for $\mathrm{Sn}$ and the other for $\mathrm{C}$ calibration. The regression coefficients are presented in Table 1.

With the influence coefficients so obtained, the Claisse-Quintin relation represents a calibration function for the $\mathrm{Sn}$ and $\mathrm{C}$ intensities, which are normalized with respect to the intensity of the selected main standard. The graphical representation of the normalized $\mathrm{Sn}$ and $\mathrm{C}$ intensities as calibration functions requires three dimensions, the composition being represented in the base plane and the normalized intensity in the direction perpendicular to this plane. A curved surface would then result for both the $\mathrm{Sn}$ and the $\mathrm{C}$ calibration functions. As this is difficult to draw on paper, the functions are represented by equivalued lines drawn in the composition plane, as shown in Fig. 1. It can be seen that the $\mathrm{Sn}$ iso-intensity ratio lines are only slightly dependent on the $\mathrm{C}$ concentration, whereas for the $\mathrm{C}$ iso-intensity ratio lines the dependence on the $\mathrm{Sn}$ concentration is very pronounced. Thus, according to expectations, $\mathrm{Sn}$ has a much greater influence on the $\mathrm{C}$ intensity than $\mathrm{C}$ has on the $\mathrm{Sn}$ intensity.

The calibration functions now serve to calculate the concentration of $\mathrm{Sn}$ and $\mathrm{C}$ for any alloy from its measured and normalized $\mathrm{Sn}$ and $\mathrm{C}$ intensity, respectively, being conjugated to each other. The conversion of such a pair of conjugated normalized $\mathrm{Sn}$ and $\mathrm{C}$ intensities into concentrations can be represented graphically by searching the point of intersection between the proper pair of $\mathrm{Sn}$ and $\mathrm{C}$ iso-intensity ratio lines. The calculation of the point of intersection was performed by means of a computer iteration procedure, with which the given ratios are traced as well as possible within the composition plane. To this end, firstly the $C$ intensity is submitted to the earlier described correction for additional background, and is normalized with respect to that main standard measurement most shortly performed before or after the measurement of the unknown alloy phase. Similarly, the $\mathrm{Sn}$ intensity is normalized with respect to its main standard intensity. Secondly, a calculated auxiliary Sn concentration on the $\mathrm{Fe}-\mathrm{Sn}$ axis is taken as a start (see Fig. 2) just to reduce the number of computer calculations. This concentration results from application of the ZAF correction procedure (MAGIC-IV computer program), which, neglecting the presence of $C$, transforms the measured $\mathrm{Sn}$ intensity into the $\mathrm{Sn}$ concentration (with pure $\mathrm{Sn}$ as a standard). Then the iteration

\begin{tabular}{lrlr}
\multicolumn{2}{c}{ Table 1. Regression coefficients } \\
& $\begin{array}{c}\text { Sn regression } \\
\text { C regression }\end{array}$ \\
$\alpha_{\text {oSn }}$ & 0.124927 & $\alpha_{\text {oC }}$ & -1.984275 \\
$\alpha_{\text {CSn }}$ & 0.169565 & $\alpha_{\text {SnC }}$ & 3.388990 \\
$\alpha_{\text {FeSn }}$ & 0.008423 & $\alpha_{\text {FeC }}$ & 4.169269 \\
$\alpha_{\text {CCSn }}$ & -2.101507 & $\alpha_{\text {SnSnC }}$ & -1.236474 \\
$\alpha_{\text {FeFeSn }}$ & -0.001945 & $\alpha_{\text {FeFeC }}$ & -2.177951 \\
$\alpha_{\text {CFeSn }}$ & 0.222582 & $\alpha_{\text {SnFeC }}$ & -3.568450 \\
\hline
\end{tabular}



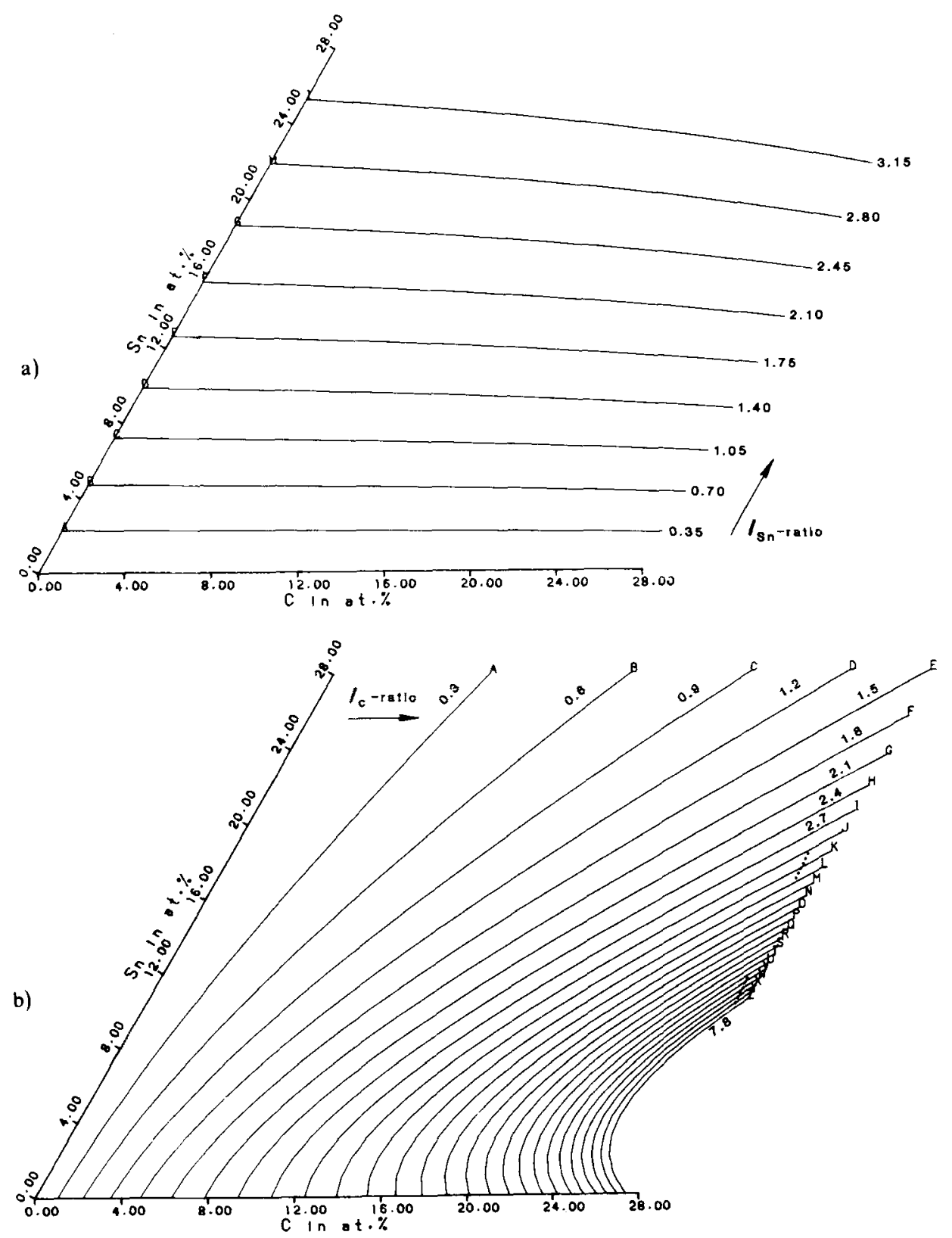

Figure 1. Representation of the $S n$ and $C$ calibration functions by iso-intensity ratio lines.

procedure is performed alternately for the $\mathrm{C}$ and $\mathrm{Sn}$ intensity ratio, in each step the tracing of the right iso-ratio line being carried out by changing only the concentration of the element under consideration. The background correction and normalization are repeated for the $\mathrm{C}$ intensity after each iteration step. Finally, the iteration is stopped when the step size in Sn and in $\mathrm{C}$ concentration is smaller than $0.0001 \mathrm{wt}-\%$ and so the composition of the phase is determined.

It should be emphasized that conversion of intensities into concentrations, using the regression coefficients obtained, is valid only for the Fe-rich part of the diagram, where the standard alloys are chosen (0-42 wt-\% Sn-0-7 wt-\% C, corresponding to $0-25$ at. $\%$ Sn-0-30 at.-\% C). Extrapolation outside this composition region may lead to errors, which in particular for $\mathrm{C}$ are not acceptable. This can be illustrated with the following example. Following the ClaisseQuintin equation for $\mathrm{Sn}$ regression the concentration of a pure $\mathrm{Sn}$ sample has been calculated. The intensity ratio $I_{\mathrm{Sn}}$ being determined as $8.31, W_{\mathrm{Sn}}$ follows from the equation

$$
W_{\mathrm{Sn}}=I_{\mathrm{Sn}} \alpha_{0 \mathrm{Sn}}=1.04
$$

$\left(W_{\mathrm{C}}=W_{\mathrm{Fe}}=0\right.$ for pure $\left.\mathrm{Sn}\right)$. This approximation appears to be fairly accurate. In contrast, extrapolation to pure $C$ is not reliable. $W_{\mathrm{Sn}}$ and $W_{\mathrm{Fe}}$ both being zero in the $\mathrm{C}$ corner of the composition triangle, the $W_{\mathrm{C}} / I_{\mathrm{C}}$ ratio becomes negative $\left(W_{C} / I_{C}=\alpha_{0 C}\right)$, which is physically inconsistent. It can be shown from the ClaisseQuintin equation for $C$ that the $W_{C} / I_{C}$ ratio is negative at higher $\mathrm{C}$ concentrations from the curved line connecting the compositions $0 \mathrm{wt}-\% \mathrm{Sn}-11.4 \mathrm{wt}-\% \mathrm{C}$ (0 at.-\% Sn-37.4 at.-\% C), 15 wt- \% Sn-9 wt-\% C (5.6 at. $-\%$ Sn-33.6 at. $\%$ C) and 50 wt- $\%$ Sn-11 wt- $\%$ C (20.7 at.-\% Sn-45.0 at.\% C). Hence the solution of $\mathrm{C}$ concentrations from intensities is restricted to the range on the left to that line. The discrepancy between 


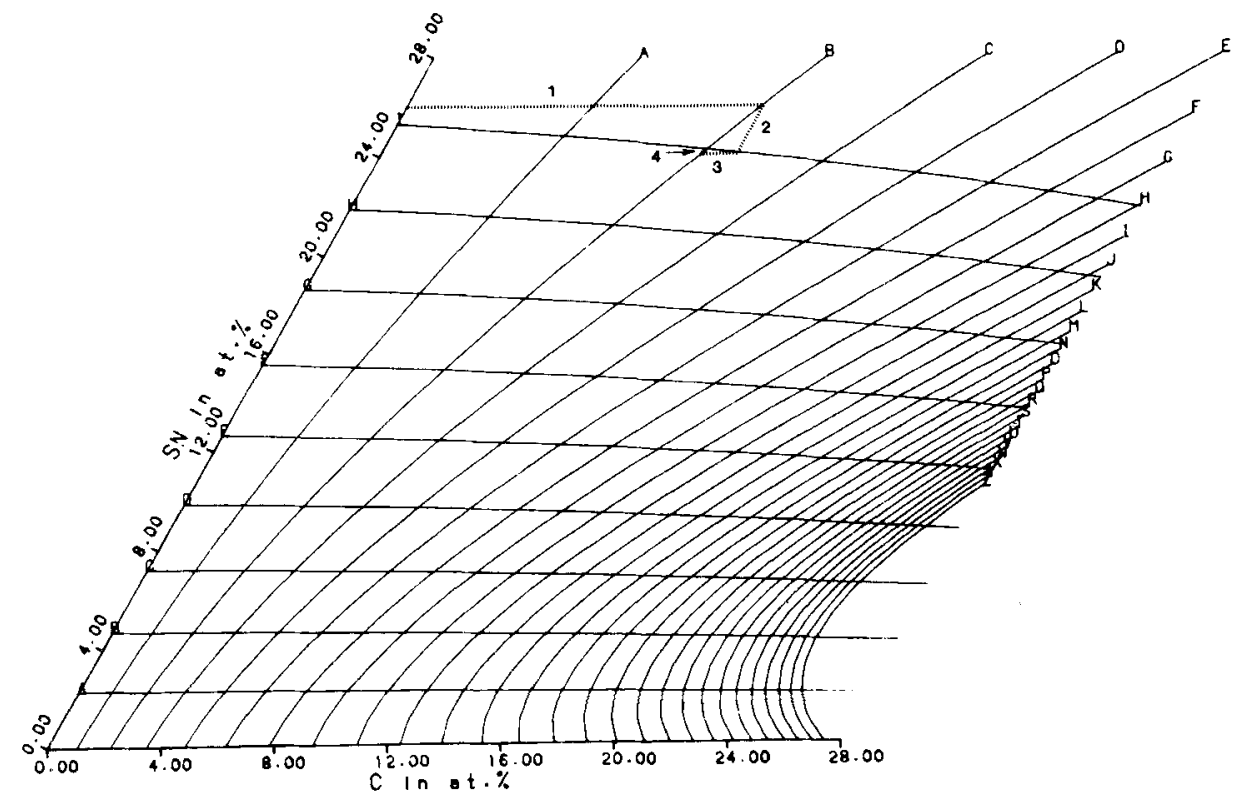

Figure 2. Example of the iteration procedure for an unknown phase with an $\mathrm{Sn}$ intensity ratio of 3.15 and a $\mathrm{C}$ intensity ratio of 0.6 , using four iterations.

the $\mathrm{Sn}$ and $\mathrm{C}$ regression with respect to extrapolation may be explained by the fact that the reference standard alloys are distributed over a wider Sn concentration range $(0-42 \mathrm{wt}-\% \mathrm{Sn})$ than the $\mathrm{C}$ concentration range $(0-7 \mathrm{wt}-\% \mathrm{C})$. Moreover, the $\mathrm{Sn}$ intensities are expected to be only slightly affected by $\mathrm{C}$, whereas the $\mathrm{C}$ intensities definitely are by $\mathrm{Sn}$. However, if only interpolation between the reference standard alloys is applied, as we did, an acceptable accuracy of the calculated concentrations can be obtained, as will be demonstrated.

It should be noted that the curves in Fig. $1 \mathrm{~b}$ show a less reliable path in the region from about 10-25 at.$\% \mathrm{C}$ up to about 12 at. $\% \mathrm{Sn}$. This may be explained in the same way as for the negative $\alpha_{0 \mathrm{C}}$, albeit restricted to the last-mentioned area. This area represents multiphase equilibria, for which no standards can be obtained. On the other hand, the fact that it concerns multiphase equilibria means that we are only interested in the conjugate compositions of the phases present. Hence, after all, actually we do not need the curves in the region, which are less reliable.

To give an indication of the accuracy of the procedure for intensity-composition conversion for samples in composition near to the standards, the reference standard data were submitted to the procedure. To that end the (chemically) analysed concentration data were taken as a start for the above-mentioned iteration procedure. The deviation between the so calculated and the analysed concentrations reflects the accuracy of the procedure. The test results are given in Table 2 , where in addition to the (chemically) analysed $\mathrm{Sn}$ and $\mathrm{C}$ concentrations and the corresponding $\mathrm{Sn}$ and $C$ ratios, the calculated concentrations, the deviation

\begin{tabular}{|c|c|c|c|c|c|c|c|c|}
\hline \multicolumn{2}{|c|}{ Sn concentration (at.-\%) } & \multicolumn{2}{|c|}{ C concentration (at.-\%) } & \multicolumn{2}{|c|}{ Sn intensity ratio } & \multicolumn{2}{|c|}{ C intensity ratio } & \multirow{2}{*}{$\begin{array}{l}\text { Number of } \\
\text { iterations }\end{array}$} \\
\hline Analysed & Calculated & Analysed & Calculated & Measured & Deviation & Measured & Deviation & \\
\hline 0.000 & 0.004 & 0.740 & 0.666 & 0.000600 & 0.000001 & 0.196824 & 0.000128 & 2 \\
\hline 0.000 & 0.000 & 1.652 & 1.930 & 0.000000 & 0.000000 & 0.540987 & 0.000059 & 2 \\
\hline 0.000 & 0.000 & 2.953 & 3.055 & 0.000000 & 0.000000 & 0.820946 & -0.000037 & 2 \\
\hline 0.000 & 0.000 & 4.530 & 4.707 & 0.000000 & 0.000000 & 1.199236 & 0.000030 & 2 \\
\hline 0.000 & 0.000 & 24.935 & 24.923 & 0.000000 & 0.000000 & 6.792749 & 0.000066 & 2 \\
\hline 0.256 & 0.258 & 3.994 & 3.834 & 0.041917 & -0.000005 & 1.000000 & 0.000018 & 2 \\
\hline 1.133 & 1.137 & 0.165 & 0.161 & 0.181829 & 0.000003 & 0.046537 & 0.000072 & 2 \\
\hline 1.795 & 1.879 & 3.378 & 3.289 & 0.299878 & 0.000006 & 0.829059 & 0.000093 & 3 \\
\hline 1.891 & 1.728 & 3.404 & 3.290 & 0.276199 & 0.000008 & 0.834763 & -0.000078 & 3 \\
\hline 2.655 & 2.843 & 4.874 & 4.729 & 0.450884 & -0.000004 & 1.106559 & -0.000034 & 3 \\
\hline 2.740 & 2.630 & 5.581 & 5.523 & 0.418814 & -0.000007 & 1.289358 & 0.000122 & 3 \\
\hline 2.870 & 2.895 & 6.194 & 6.387 & 0.460867 & 0.000008 & 1.457755 & 0.000046 & 3 \\
\hline 5.204 & 5.355 & 0.143 & 0.146 & 0.820288 & 0.000004 & 0.030892 & 0.000007 & 2 \\
\hline 6.765 & 6.604 & 0.499 & 0.502 & 1.000000 & 0.000009 & 0.094002 & 0.000107 & 3 \\
\hline 16.643 & 16.632 & 28.134 & 28.147 & 2.623447 & -0.000004 & 4.072830 & 0.000012 & 3 \\
\hline 22.339 & 22.709 & 12.792 & 12.946 & 3.100987 & -0.000009 & 0.747389 & -0.000005 & 4 \\
\hline 23.318 & 22.964 & 12.306 & 12.148 & 3.118609 & -0.000004 & 0.683806 & -0.000021 & 4 \\
\hline 25.374 & 25.401 & 0.000 & 0.000 & 3.250837 & -0.000000 & 0.000000 & 0.000000 & 2 \\
\hline
\end{tabular}




\section{W. FREDRIKSZ, H. KOSTER AND B. H. KOLSTER}

in the ratios and the number of iterations are shown. As can be seen, the calculated concentrations show a relative deviation from the analysed data of less than or equal to about $5 \%$, except for the alloys $\mathrm{Fe}-1.89$ at. $-\% \mathrm{Sn}-3.40$ at. $-\% \mathrm{C}(8.5 \%$ relative deviation in $\mathrm{Sn})$ and $\mathrm{Fe}-0$ at. $-\% \mathrm{Sn}-1.65$ at. $-\% \mathrm{C}(16.6 \%$ relative deviation in $\mathrm{C}$ ), which, in the last two cases may indicate the presence of inhomogeneous alloys. Hence the relative accuracy of the EPMA quantification method followed is about $5 \%$.

\section{CONCLUSIONS}

The use of the Claisse-Quintin relation with constant influence coefficients for the quantification of EPMA measurements of the system $\mathrm{Fe}-\mathrm{Sn}-\mathrm{C}$ results in calibration functions for $\mathrm{Sn}$ and $\mathrm{C}$ that confirm the great influence of $\mathrm{Sn}$ on the $\mathrm{C}$ intensity and almost no influence of $\mathrm{C}$ on the $\mathrm{Sn}$ intensity. In order to convert the intensities into concentrations by means of the calibration functions, the computerized iteration procedure applied turns out to be a most satisfactory route, resulting in a relative accuracy of about $5 \%$.

\section{Acknowledgements}

The authors thank the members of the chemical analysis laboratory of the Chemical Technology Department for the chemical analyses of the alloys. They also express their gratitude to Prof. J. D. Brown, University of Western Ontario, London, Canada, for valuable discussions and advice.

\section{REFERENCES}

1. W. Fredriksz, Thesis, Twente University of Technology, Enschede, The Netherlands (1983).

2. J. I. Goldstein and J. W. Colby, in Practical Scanning Electron Microscopy, edited by J. I. Goldstein and $H$. Yakowitz, Chapt. XII, pp. 435-489. Plenum Press, New York (1975).

3. R. Jenkins, Adv. X-ray Anal. 19, 1 (1976).

4. J. W. Colby, 6th National Conference on Electron Probe Microanalysis (1971) paper No. 17.

5. W. K. de Jongh, Norelco Rep. 23, 26 (1976).

6. J. D. Brown and L. Parobek, X-ray Spectrom. 5, 36 (1976).

7. L. Parobek and J. D. Brown, $X$-ray Spectrom. 7, 26 (1978).

8. A. P. von Rosenstiel, P. Schwaab and J. D. Brown, Mikrochim. Acta Suppl. 10, in press.

9. G. R. Lachance and R. J. Traill, Can. Spectrosc. 11, 43 (1966).

10. T. O. Ziebold and R. E. Ogilvie, Anal. Chem. 36, 322 (1964).

11. S. D. Rasberry and K. F. J. Heinrich, Anal. Chem. 46, 81 (1974).
12. K. F. J. Heinrich, Adv. X-ray Anal. 19, 75 (1976).

13. F. Claisse and M. Quintin, Can. Spectrosc. 12, 129 (1967).

14. R. Rousseau and F. Claisse, X-ray Spectrom. 3, 31 (1974).

15. R. Tertian, Adv. X-ray Anal. 19, 85 (1976).

16. G. R. Lachance and F. Claisse, Adv. X-ray Anal. 23, 87 (1980).

17. D. F. Wood and R. T. Clark, Analyst (London) 82, 624 (1957)

18. G. Gopala Rao and V. Narayama Rao, Z. Anal. Chem. 147, 338 (1955).

19. H. E. Bishop, Rep. UK At. Energy Auth., AERE-R8627, AERE, Harwell (1976).

20. G. L. Fisher and G. D. Farningham, 'Quantitative Carbon Analysis of Nickel Steels with the Electron Probe Microanalyzer,' paper presented at ASM Materials Engineering Congress, Cleveland, Ohio (1972).

Received 4 October 1983; accepted (revised) 25 June 1984 